\title{
Núcleo de Estudos de Política e Gestão da Educação da UFRGS: linhas convergentes e paralelas
}

\author{
UFRGS Center for Educational Policy and Management \\ Research:convergent and parallel lines
}

\author{
Maria Beatriz Luce ${ }^{1}$ \\ Nalú Farenzena² \\ Vera Maria Vidal Peroni ${ }^{3}$ \\ Naira Lisboa Franzoi \\ Juca Gil5
}

\section{Resumo:}

O texto descreve o Núcleo de Estudos de Política e Gestão da Educação da Universidade Federal do Rio Grande do Sul, desde sua criação, em 1992, até a atualidade, dando relevo aos âmbitos do ensino, da produção científica, da pesquisa, da extensão universitária, das relações com a comunidade acadêmica nas atividades de pesquisa e da inserção de seus integrantes em ações de caráter político e acadêmico-administrativo. A história do Núcleo é tecida com a participação de muitos atores, na academia e fora dela, com linhas de ação e reflexão costuradas pelo propósito de contribuir para a democratização da educação e do Estado.

Palavras-chave: grupos de pesquisa em educação; políticas educacionais; gestão da educação; Núcleo de Estudos de Política e Gestão da Educação; Universidade Federal do Rio Grande do Sul.

\begin{abstract}
:
This text presents the research group called Núcleo de Estudos de Política e Gestão da Educação, i.e. the Center for Educational Policy and Management Research at the Federal University of Rio Grande do Sul, which was created in 1992. The most important teaching, research and extension activities involving its faculty and students are described and commented, stressing the academic, political and administrative relationships that have evolved within and from the projects developed. It is evidenced that the Center's history was weaved with the participation of many academic and non-academic (professional and citizenship leaders) actors in the various projects, which had the democratization of education and of the State as a major guideline.
\end{abstract}

Keywords: research groups in education; educational policy; educational management; Núcleo de Estudos de Política e Gestão da Educação; Universidade Federal do Rio Grande do Sul.

1 Doutora em Educação, professora da Faculdade de Educação da UFRGS. E-mail: lucemb@ufrgs.br

2 Doutora em Educação, professora da Faculdade de Educação da UFRGS. E-mail: nalu.farenzena@gmail.com

3 Doutora em Educação, professora da Faculdade de Educação da UFRGS. E-mail: veraperoni@gmail.com

4 Doutora em Educação, professora da Faculdade de Educação da UFRGS. E-mail: nairalf@yahoo.com.br

5 Doutor em Educação, professor da Faculdade de Educação da UFRGS. E-mail: jucagil@uol.com.br 
O Núcleo de Estudos de Política e Gestão da Educação (Núcleo, daqui por diante) da Universidade Federal do Rio Grande do Sul (UFRGS) congrega atividades de ensino, pesquisa e extensão de cinco docentes - os autores deste texto - e seus orientandos de iniciação científica, mestrado e doutorado; e, eventualmente, com bolsistas de pós-doutorado, professores visitantes e outros pesquisadores colaboradores. Estas atividades integram o setor de conhecimento Política e Gestão da Educação, no Departamento de Estudos Especializados da Faculdade de Educação - do qual fazem parte dez docentes - e a linha de pesquisa Políticas e Gestão de Processos Educacionais, no Programa de Pós-Graduação em Educação (PPGEDU), igualmente formada por dez docentes.

Sua criação ocorreu em 1992 sob a denominação de Núcleo de Estudos de Política e Planejamento da Educação. A mudança do nome ocorreu em 2000 pelo fato de que o planejamento passara a ser secundarizado, reflexo de uma inflexão ocorrida nas prioridades temáticas de pesquisa da área em nível nacional - de certo modo, o planejamento passou a ser entendido como processo ou fase integrante da gestão. De outra parte, o próprio termo gestão ganhou força com o reconhecimento da gestão democrática como princípio do ensino disposto na Constituição da República em 1988, num movimento eminentemente político de superação da administração de base ideologicamente empresarial e do planejamento centralizado e economicista da educação.

O Núcleo foi criado por Maria Beatriz Luce. De 1992 em diante, os demais professores foram chegando: Nalú Farenzena em 1995, Vera Peroni em 2001, Naira Lisboa Franzoi em 2003 e Juca Gil em 2010. No diretório grupos de pesquisa, do CNPq, mantemos o registro do grupo Núcleo de Estudos de Política e Gestão da Educação, cuja composição, ao longo dos anos, tem variado bastante, segundo vínculos e colaborações em pesquisa colocados nos períodos de atualização de informações na plataforma.

O trabalho do Núcleo articula-se a partir de conceitos/princípios como democratização, inclusão social, gestão democrática, justiça social.

As investigações produzidas focalizam as políticas públicas de educação, entendidas como fluxos de ação/ decisão do Estado delimitados por um campo de possibilidades que envolve interações entre os agentes governamentais e a sociedade civil, a configuração institucional do Estado e da área da educação e o ordenamento jurídico, no que tange a direitos, garantias e condições de escolarização e formação profissional. Assim, o quadro compreensivo abarca o conteúdo material das decisões políticas, como também a dimensão institucional/organizacional e o processo relacional envolvidos nas políticas.

Os estudos abrangem dimensões de diagnóstico, análise, comparação e avaliação de políticas públicas de educação, em geral com metodologias de caráter qualitativo, e utilizam uma perspectiva multidisciplinar, principalmente referenciais da filosofia política, da teoria educacional, da sociologia, da ciência política, da análise de políticas públicas, da administração, da economia, do direito e da antropologia.

Com base nos conceitos/princípios já enunciados, os estudos do Núcleo têm focalizado questões no campo das políticas públicas de educação como: direito à educação e cidadania; redefinições do papel do Estado e políticas educacionais; reordenamento da esfera pública e ordenamento constitucional, legal e institucional da educação; federalismo, centralização, descentralização e participação; relações entre o setor público e o setor privado na educação; relações intergovernamentais; qualidade da educação; avaliação de políticas e de instituições de educação básica, superior e profissional; financiamento público da educação; accountability das ações públicas na educação; interfaces de políticas de educação e de trabalho; integração/regionalização latino-americana.

É comum aos estudos a preocupação com o contexto, quer dizer, a compreensão das políticas - sejam elas institucionais, locais, regionais ou globais - em perspectiva sócio-histórica. Outro substrato comum é o reconhecimento de que o saber acadêmico deve contribuir para avanços na afirmação dos direitos à educação, no âmbito jurídico e/ou na prática político-administrativa. Assim, as desigualdades e iniquidades sociais e educacionais, imersas num campo de tensão que compreende marcadores espaciais, de classe, de raça/etnia ou de gênero, são tomadas como problemas complexos que devem ser objeto de estudo e intervenção, tendo como horizontes a democratização da educação - nos aspectos do acesso, da gestão e da cultura - e a emancipação e justiça sociais. 
Os estudos produzidos pelo Núcleo têm por objetivo contribuir para o conhecimento, o debate acadêmico e o planejamento e acompanhamento das políticas públicas de educação no Rio Grande do Sul, no Brasil e na América Latina. Contudo, o diálogo com colegas de outras partes da América e de outros continentes tem sido também valorizado, considerando-se a dinâmica da globalização como condicionante das atuais políticas e instituições educacionais, como também o potencial dos estudos comparativos e da perspectiva internacional.

O Núcleo desenvolve projetos de pesquisa a partir da avaliação de relevância e necessidade de avanço do conhecimento das políticas e do campo teórico. Com o intuito de contribuir mais diretamente para a formulação e implementação de políticas públicas, realiza pesquisas, atividades de extensão e de ensino mediante convênios e colaborações com instituições públicas e organizações da sociedade civil.

Na sequência apresentam-se campos de atuação, temas, projetos e publicações que exemplificam a produção e os interesses deste coletivo acadêmico-científico.

\section{Atividades de ensino}

A descrição desse item compreenderá a atuação nos cursos de graduação da UFRGS, em cursos de pósgraduação lato sensu e stricto sensu na UFRGS e em outras instituições, bem como um panorama referente às teses e dissertações orientadas.

\section{Graduação}

Os professores do Núcleo atuam em cursos de licenciatura. As disciplinas ofertadas na Pedagogia são Organização e Gestão da Educação, Políticas e Legislação da Educação e o Seminário Gestão de Espaços Escolares e Não Escolares. Nas demais licenciaturas são Políticas da Educação Básica, Organização da Escola

Básica e Políticas Governamentais da Educação Brasileira. Todas elas têm como bases a compreensão da educação escolar como direito de cidadania e como dever do Estado e a perspectiva da gestão democrática.

Na Pedagogia, desde a reforma curricular de 2007, a carga horária da área de Política e Gestão da Educação foi ampliada, contemplando três disciplinas que integram um eixo chamado Gestão da Educação: Espaços Escolares e Não Escolares, com sete disciplinas, no terceiro semestre do curso. A proposta é que haja uma interdisciplinaridade entre os componentes do eixo e fica a cargo do Seminário Gestão da Educação: Espaços Escolares e Não Escolares a articulação entre teoria e prática. A efetivação da proposta tem se constituído num desafio.

Cabe destacar que, entre os anos de 2006 a 2011, nos envolvemos no planejamento e efetivação do curso de Pedagogia na modalidade educação à distância, oferecido pela Faced/UFRGS, como programa, com financiamento do Ministério da Educação e envolvendo convênio entre a Faced/UFRGS, o Centro de Ciências da Educação da Universidade Federal de Santa Catarina e cinco prefeituras gaúchas. Os estudantes, em torno de 370, eram professores em exercício no ensino fundamental das redes estadual e municipais. Nesse curso participamos da comissão de coordenação inicial e coordenamos a fase de elaboração do material das disciplinas Organização e Gestão da Educação e Organização do Ensino Fundamental, do quinto semestre. No desenvolvimento do curso, nossa participação se efetivou por meio do trabalho de orientandos e ex-orientandos de mestrado e doutorado, os quais assumiram funções de docência e orientação de trabalhos de conclusão de curso. Esta experiência, com sentido de produção e sistematização de conhecimentos junto à prática dos professores e gestores de escolas públicas, foi também muito positiva em sua dimensão de formação para futuros docentes da educação superior.

Nas demais licenciaturas, desde 2007 são oferecidas as disciplinas Políticas da Educação Básica, Organização da Escola Básica e Políticas Governamentais da Educação Brasileira, cada qual com dois créditos. As duas primeiras originaram-se da disciplina Organização da Educação Brasileira, a qual tinha quatro créditos e integrava conteúdos de políticas, organização e gestão da educação. A divisão levou a uma diferenciação artificial de dimensões - política e organização - que são, de fato, intimamente relacionadas. Isso se constitui numa dificuldade na medida em que os alunos 
são de cursos com currículos muito diferentes na formação pedagógica, em função da autonomia das coordenações de curso: alguns cursam apenas uma das disciplinas; não há uma sequência que seja comum aos cursos. Isto tem levado à superposição ou repetição de conteúdos. A disciplina Políticas Governamentais foi pensada como componente curricular de caráter complementar para enfocar políticas emergentes com estudantes que já tivessem cursado as outras duas. No entanto, para alguns cursos essa é a única disciplina na área, acarretando problema similar ao referido.

\section{Coordenação ou participação em cursos de especialização}

O Núcleo de Estudos de Política e Gestão da Educação tem sido a base da oferta de cursos de pósgraduação nesta área de conhecimento e de formação profissional para a gestão/administração escolar e de sistemas e projetos educacionais.

Integramos a coordenação de quatro edições do Curso de Especialização em Gestão da Educação, entre os anos de 1999 e 2007. A ideia originária deste foi a oferta de formação continuada para diretores de escolas estaduais, em 1996, em função da lei estadual que regula a eleição de diretores e o exercício de cargo de diretor. Nas quatro edições do curso o acesso não ficou restrito a diretores, mas nos mobilizou a intenção de contribuir para a formação de gestores num contexto de democratização da gestão da educação.

Em duas edições do Curso de Especialização em Gestão Escolar, entre 2008 e 2011, professores do Núcleo assumiram funções de coordenação. Esse curso faz parte do Programa Nacional Escola de Gestores da Educação Básica na modalidade à distância, vinculado ao MEC, na sua terceira edição. Na primeira edição contemplou 400 diretores de escolas públicas estaduais e municipais do Rio Grande do Sul, na segunda, 700 diretores e na terceira, mais 400 diretores. A implantação do curso na UFRGS foi uma ação conjunta entre o Núcleo e o Centro Interdisciplinar de Novas Tecnologias na Educação (Cinted). Na atual edição (2012-2013) parte significativa dos professores é composta de ex-orientandos ou orientandos de mestrado ou doutorado dos professores do Núcleo.

Como parte do mesmo projeto, atualmente o Núcleo participa da implantação de um curso nos mesmos parâmetros para coordenadores pedagógicos, atendendo 500 profissionais de escolas estaduais e municipais do Rio Grande do Sul.

É importante assinalar a dimensão política e de intervenção permitida pelos dois cursos mencionados da Escola de Gestores, já que ensejam uma estreita relação tanto com o CONSED e a UNDIME na sua promoção, como um diálogo de pesquisa e formação com diretores de escolas públicas estaduais e municipais. Os cursos têm como foco a gestão democrática e procura estabelecer a relação teoria-prática, já que, além da parte teórica, os diretores devem realizar um trabalho prático envolvendo a comunidade escolar. Articulada ao curso foi realizada a pesquisa "Gestão educacional do Rio Grande do Sul".

Também a coordenação da primeira edição do Curso de Especialização em Educação Profissional Integrada à Educação Básica na Modalidade Educação de Jovens e Adultos (Proeja), entre 2006-2007, esteve com docentes do Núcleo. Nas duas edições que se seguiram estivemos presentes como docentes. Este é um dos muitos cursos em que os professores e colaboradores do Núcleo atuaram ou atuam em cursos de pós-graduação lato sensu focalizados em outros temas, mas que contemplam conhecimentos de políticas públicas e de gestão da educação, ou então cursos na área de gestão educacional coordenados por outros grupos da própria UFRGS ou de outras universidades públicas federais: na UFRGS, Educação Infantil, Educação de Jovens e Adultos, Gestão Interdisciplinar da Educação, Educação Especial e Processos Inclusivos, Educação Social, Educação de Privados de Liberdade, Ética e Educação em Direitos Humanos, Educação para a Diversidade; em outras instituições, Gestão Escolar (Universidade Federal de Pelotas) e Educação Integral - Mais Educação (Universidade Federal da Fronteira Sul).

A contribuição deste Núcleo para o desenvolvimento da pós-graduação em lato e stricto sensu de áreas correlatas também é reconhecida na UFRGS, sendo exemplos a participação em cursos de administração, administração pública, relações do trabalho, lazer e recreação, e políticas sociais para idosos. 
Mestrado e doutorado

O Núcleo tem sua origem na criação do Programa de Pós-Graduação em Educação da UFRGS (PPPGEdu), em 1972, com a área de concentração em Planejamento Educacional. Atualmente, como referido, integra a linha de pesquisa Políticas e Gestão de Processos Educacionais que é articulada no eixo Políticas de Formação, Políticas e Gestão da Educação.

As atividades de ensino dedicadas à formação de mestres e doutores em educação são também abertas à participação de estudantes de outras áreas da UFRGS e de outras instituições conveniadas.

Dentre as disciplinas e seminários avançados oferecidos nos anos mais recentes pelos professores deste Núcleo encontram-se como temas principais: análise de políticas públicas de educação, políticas públicas e gestão da educação superior no Brasil, Estado e políticas educacionais, redefinições no papel do Estado: público/privado e gestão da Educação. De acordo com as necessidades de formação dos estudantes são também oferecidas práticas de pesquisa e leituras dirigidas sobre temas mais específicos.

Destaca-se que a demanda pelo doutorado e mestrado tem ultrapassado em muito nossa capacidade de atendê-la. Isso é para nós particularmente importante porque por meio da formação é estabelecida uma estreita articulação com as escolas de educação básica, uma vez que nossos orientandos, na quase totalidade, nelas atuam como docentes/gestores. Além disso, os cursos têm sido muito significativos na formação de quadros para a educação superior, haja vista que os orientados têm se encaminhando para instituições desse nível.

\section{Sobre dissertações e teses defendidas}

O registro histórico do PPPGEdu vincula este Núcleo à experiência acumulada em orientação de teses e dissertações desde 1984, quando foi concluída a primeira dissertação de mestrado orientada por Maria Beatriz Luce. Desde então, estiveram sob sua supervisão 26 mestres e 21 doutorados em Educação, todos estes com pesquisas no campo das políticas públicas e da gestão de instituições de educação básica e de educação superior. São marcantes as linhas de investigação sobre a organização do sistema federativo de ensino no Brasil e os processos de regulação e avaliação institucional pautados pela gestão democrática e o regime de colaboração e as políticas de financiamento, de formação e valorização docente e de inovação curricular.

Sob a orientação de Nalú Farenzena foram concluídas 12 dissertações e seis teses, entre 2005 e 2012. Os estudos abrangeram as temáticas do financiamento da educação, custos da educação, accountability das ações do Estado, direito à educação e políticas públicas específicas da educação básica. Contemplaram diferentes espaços: municípios (vários do Rio Grande do Sul e Manaus), Distrito Federal, rede estadual de ensino do Rio Grande do Sul, Brasil, países da América Latina. Predominaram metodologias qualitativas, às vezes com uso de indicadores quantitativos processados com estatística descritiva básica; as pesquisas utilizaram uma ou a combinação das seguintes metodologias: estudos de casos múltiplos, análise de conteúdo, análise documental, estudo comparado, análise de política pública, avaliação de política pública.

Sob a orientação de Vera Peroni foram concluídas 11 dissertações e seis teses entre 2005 e 2012. Os estudos abrangeram principalmente temáticas vinculadas ao público- privado, gestão da educação e políticas educacionais municipais, estaduais, nacionais e latino-americanas. O grupo de orientandos desenvolve coletivamente aprofundamento teórico-metodológico sobre as redefinições no papel do Estado e como se materializam na política educacional, através dos diferentes objetos de estudo do grupo. A maioria dos orientandos participa também de grupo de pesquisa sobre público-privado.

Sob a orientação de Naira Lisboa Franzoi foram concluídas 10 dissertações entre 2008 e 2012. As dissertações abordaram diferentes aspectos das políticas de educação profissional, tanto na esfera da educação escolar quanto de outros tipos de formação em que estão inseridos os trabalhadores, jovens ou adultos. Além da análise de políticas, várias dessas pesquisas mergulharam no universo dos estudantes trabalhadores e, para 
tanto, lançaram mão de metodologias variadas, inspiradas especialmente em estudos etnográficos. O grupo de pesquisa desenvolveu várias metodologias de produção de dados e análise, tais como trajetórias de vida e trabalho, etnofotografia, troca de cartas entre pesquisador(a) e estudantes, dentre outras. Estão em andamento três teses de doutorado que têm ênfase em políticas de educação profissional implantadas recentemente como o Ensino Médio Politécnico e a Rede Certific - política de certificação de saberes experienciais de trabalhadores -, de responsabilidade dos governos estadual e federal respectivamente.

\section{Produção Acadêmica}

A produção intelectual dos professores e estudantes congregados no Núcleo revela regularidade no trabalho acadêmico-científico, abrangência do campo de conhecimentos e também uma atualização (ou renovação) dos temas e problemas de pesquisa.

A dinâmica de publicações, em geral, tem início com a apresentação de textos e pôsteres em salões de iniciação científica e em congressos qualificados pela área de Educação, como os promovidos pela ANPED e pela ANPAE, no País; no âmbito do Mercosul, pela AUGM (Associação de Universidades Grupo de Montevidéu); e mais amplamente por redes de pesquisa vinculadas a projetos ALFA (União Europeia - América Latina) ou na LASA (Latin American Studies Association). Contudo, os trabalhos mais consolidados têm sido apresentados em diversos foros e periódicos de nível nacional e internacional, proporcionando a este grupo crescente visibilidade e diálogos que fertilizam a formação e a produção intelectual dos professores e estudantes.

Na disseminação do conhecimento na área de Política e Gestão da Educação, o Núcleo é reconhecido por sua contribuição na criação e desenvolvimento de periódicos que se destacam como espaços de interlocução entre a academia e os profissionais. A RBPAE (Revista Brasileira de Política e Administração da Educação), desde sua criação em 1983, recebe franco apoio dos professores e estudantes vinculados ao Núcleo, inclusive tendo assumido funções de editoria e secretaria do periódico na maior parte dos seus 29 anos de ininterrupta publicação. Mais recentemente (2011), a FINEDUCA (Revista de Financiamento da Educação) igualmente tem neste Núcleo esteio editorial. Ademais, cumpre mencionar o apoio que professores do Núcleo empenham à revista Educação \& Realidade, da Faculdade de Educação da UFRGS; e à Poled - Políticas Educativas do Núcleo Educação para a Integração, da AUGM.

No ano de 2006, o Núcleo instituiu com a Editora da UFRGS a Coleção Política e Gestão da Educação. Nesta, já foram publicadas sete obras que revelam grande parte da produção realizada por professores e estudantes vinculados, mas também a contribuição de outros grupos de pesquisa associados nos estudos sobre educação escolar no Rio Grande do Sul:

- Gestão democrática da educação: concepções e vivências. Coletânea organizada por Maria Beatriz Luce e Isabel Letícia Pedroso de Medeiros, 2006. Contém CD/DVD. Esgotado.

- A política de financiamento da educação básica: rumos da legislação brasileira. De Nalú Farenzena, 2006.

- Dilemas da educação brasileira em tempos de globalização neoliberal. Coletânea organizada por Vera Maria Vidal Peroni, Vera Lúcia Bazzo e Ludimar Pegoraro, 2006.

- Entre a formação e o trabalho: trajetórias e identidades profissionais. De Naira Lisboa Franzoi, 2006.

- A Campanha de alfabetização em Cuba. De Vera Maria Vidal Peroni, 2006.

- Gestão Educacional e Democracia Participativa. Coletânea organizada por Álvaro Moreira Hypólito, Maria Cecília Lorea Leite, Maria Antonieta Dal'Igna e Valdinei Marcola, 2008.

- Rosa-dos-ventos: traços da formação docente pós-LDB. De Edite Maria Sudbrack, 2009.

A produção do Núcleo também tem sido veiculada por outras editoras ou instituições. Dessa produção, fazemos alguns destaques a seguir:

- A educação municipal em 1992: a organização dos sistemas municipais e ensino no Rio Grande do Sul. Porto 
Alegre: UFRGS, 1993. 58p. Livro de autoria de Maria Beatriz Luce, Nalú Farenzena e Marisa Timm Sari. Porto Alegre: Faced/UFRGS, Conseme, UEC/FAMURS, 1993.

- A educação no Rio Grande do Sul. Livro de autoria de Maria Beatriz Luce. Brasília: UNICEF, 2000.

- Política educacional e papel do Estado no Brasil dos anos 90. Livro de autoria de Vera Peroni. São Paulo: Xamã, 2003.

- Formula funding of schools, decentralization \& corruption. Livro de autoria de Rosalind Levacic e Peter Downes, com base em registros de pesquisa elaborados por pesquisadores de diferentes países, entre eles Maria Beatriz Luce e Nalú Farenzena. Paris: International Institute for Educational Planning, 2004.

- O público e o privado na educação: interfaces entre Estado e sociedade. Livro organizado por Vera Peroni e Theresa Adrião. São Paulo: Xamã, 2005.

- Custos e condições de qualidade da educação em escolas públicas: aportes de estudos regionais. Coletânea organizada por Nalú Farenzena. Brasília: INEP/MEC, 2006.

- Reflexões sobre a prática e a teoria em PROEJA: produções da Especialização PROEJA/RS. Coletânea organizada por Naira Lisboa Franzoi em co-autoria com outros professores da UFRGS. Porto Alegre: Evangraf, 2007.

- Programa Dinheiro Direto na Escola: uma proposta de redefinição do papel do Estado na educação? Livro do relatório final da pesquisa nacional coordenada por Vera M. Vidal Peroni e Theresa Adrião, publicado pelo Instituto Nacional de Estudos e Pesquisas Educacionais Anísio Teixeira (INEP), Brasília, 2007.

- Trabalho, trabalhadores e educação: conjeturas e reflexões. Livro organizado por Naira Lisboa Franzoi juntamente com alunos do pós-graduação. Porto Alegre: Evangraf, 2010. Embora este tenha sido um livro de pequena circulação foi aqui citado pelo fato de ter sido uma importante experiência de publicação dos trabalhos finais de uma disciplina do PPGEDU, por iniciativa dos próprios alunos. Avaliou-se que artigos publicados dos alunos incentivaram-os a qualificarem sua produção na disciplina.

- Seção Temática Educação de Jovens e Adultos e Educação Profissional da Revista Educação \& Realidade, v. 35, n. 1, jan./abr. 2010. Organizada por Naira Lisboa Franzoi e Maria Margarita Machado.

- Implementação de planos de ações articuladas municipais: uma avaliação em quatro estados brasileiros. Livro organizado por Nalú Farenzena. Pelotas: Editora e Gráfica Universitária/UFPel, 2012.

- Público e o Privado na Educação: novos elementos para o debate. Livro organizado por Vera Peroni e Theresa Adrião. São Paulo: Xamã, $1^{a}$ ed. em 2008 e 2 ed. em 2012.

Além destas obras produzidas pelos professores do Núcleo, sua produção e a de seus orientandos está presente em livros avulsos ou seriados, bem como em periódicos, editados no Brasil e no estrangeiro.

\section{Projetos de Pesquisa}

Optamos por apresentar aqui uma seleção dos projetos de pesquisa desenvolvidos ou em desenvolvimento que foram escolhidos em função de sua maior abrangência, ou por ilustrarem as temáticas que têm sido por nós priorizadas e também colaborações com governos, entidades e redes de pesquisadores. Identificamos períodos de execução e foco e, quando pertinente, fontes de financiamento e parcerias.

Um primeiro conjunto de projetos diz respeito a pesquisas que envolveram todos ou quase todos os professores do Núcleo no período em que foram realizados, ou, ainda, um grupo expressivo de orientandos ou ex-orientandos de mais de um professor:

- Projeto Especial Multinacional de Desenvolvimento Educacional Integrado em Zonas Desfavorecidas ou Limítrofes. Projeto de investigação e ação da OEA realizado no período de 1988 a 1992 pela Faculdade de Educação da UFRGS, em representação (convênio) do Ministério da Educação do Brasil.

- Financiamento da educação infantil e do ensino fundamental nos municípios do Rio Grande do Sul: um estudo das fontes e usos de recursos e dos custos educacionais. Período: 1995 a 1998. Financiado pelo 
Unicef. Desenvolvido em parceria com o Conselho dos Secretários Municipais de Educação do Rio Grande do Sul. Buscou identificar fontes e usos dos recursos financeiros e custos educacionais diretos e indiretos de uma amostra de 26 redes e 52 escolas municipais do Rio Grande do Sul.

- Avaliação do Processo de Implementação e do Impacto das Ações do Projeto de Educação Continuada da Secretaria de Estado da Educação de São Paulo. Desenvolvido no período de 1997 a 1999. Financiado pelo PNUD. Elaboração de avaliação do processo de implementação e do impacto de um projeto de educação continuada de professores da rede estadual de São Paulo. Envolveu dimensões qualitativas e quantitativas e cinco dos pólos abrangidos pelo projeto de capacitação.

- Processo de implantação e impacto do Fundef em estados e municípios: casos e comparações com vistas a uma avaliação. Período: 1998 a 2002. Financiado pela Fundação Ford. Estudo realizado por uma rede nacional de pesquisadores, originando um amplo conjunto de produtos, como: banco de dados educacionais e financeiros; relatórios estaduais e estudos sobre o Fundef em 12 estados e 80 municípios.

- Fundo de Manutenção e Desenvolvimento do Ensino Fundamental e de Valorização do Magistério no Rio Grande do Sul: acompanhamento e avaliação do impacto. Período: 1998 a 2002. Pesquisa avaliativa da implementação e impacto do Fundef no Rio Grande do Sul, abrangendo uma caracterização geral e quatro estudos de caso.

- Ensino Médio Noturno: registro e análise de experiências no Rio Grande do Sul. Período: 2003 e 2004. Financiado pela UNESCO. Iniciativa e coordenação do MEC. Visou subsidiar a formulação de políticas, programas, planos e ações para a melhoria do ensino médio noturno no Brasil. Foram realizados estudos de caso em 12 escolas públicas estaduais do Rio Grande do Sul.

- Levantamento de custo-aluno-ano em escolas de educação básica que oferecem condições para a qualidade do ensino. Período: 2003 e 2004. Financiado pelo INEP/MEC. Iniciativa e coordenação do INEP/MEC. O estudo realizou o levantamento e avaliação dos principais componentes do custo aluno/ano e características de gestão e organização de onze escolas de educação básica do Estado do Rio Grande do Sul.

- Experiências Inovadoras de Educação Básica de Nível Médio integrada à Educação profissional. Período: 2003 e 2004. Financiado pela UNESCO. Iniciativa e coordenação do MEC. Mapeamento, descrição de experiências de oferta de ensino médio e profissional oferecido por sindicatos, movimentos, organizações não-governamentais e empresas do Rio Grande do Sul e Santa Catarina.

- Plano de Metas Compromisso Todos pela Educação: análise e avaliação da política em redes públicas municipais brasileiras. Período: iniciado em 2008. Financiado em parte com recursos do FNDE. Análise de referenciais e processos da política Plano de Metas Compromisso Todos pela Educação e avaliação dos processos de elaboração e de implementação do Plano de Ações Articuladas em municípios do Rio Grande do Sul, de Santa Catarina, de Alagoas e da Paraíba.

Um segundo conjunto de projetos de pesquisa selecionados contempla estudos desenvolvidos pelos professores do Núcleo que não tiveram o caráter coletivo referido anteriormente, mas foram implementados em colaboração com estudantes de iniciação científica, mestrado e doutorado da UFRGS ou com pesquisadores e redes de pesquisadores de outras instituições.

- Avaliação do Projeto Principal da Unesco para a América Latina e o Caribe, no Brasil - balanço de 20 anos (1980-2000) e prospectiva. Pesquisa encomendada pela UNESCO/Brasil para integrar uma avaliação coordenada pelo Unesco/Orealc; projeto desenvolvido em 2000-2001.

- Programa Dinheiro Direto na Escola: uma proposta de redefinição do papel do Estado na educação? Período: 2003 a 2005. Financiado pelo CNPq. Caracterização do programa do governo federal "Dinheiro Direto na Escola" e análise de suas implicações para a organização e o funcionamento da escola pública, decorrente da constituição de unidades executoras como entidades de direito privado. Projeto iniciado no Rio Grande 
do Sul e ampliou para as cinco regiões com a pesquisa nacional "O Programa Dinheiro Direto na Escola: uma redefinição do papel do Estado na educação" (coordenada por Vera Peroni e Thereza Adrião, 2007).

- Demanda, oferta e condições da formação de professores no Rio Grande do Sul. Período: 2003-2005. Análise, em perspectiva histórico-comparativa e situacional, da oferta de formação inicial (cursos de licenciatura) e continuada de professores no estado do Rio Grande do Sul, com atenção à demanda e às condições institucionais de qualidade.

- Reconfigurações do Estado: conexões entre o público e o privado. Período: 2005-2009. Análise de mudanças ocorridas no papel do Estado e as conexões entre o público e o privado, através do estudo dos programas da Rede Vencer, coordenados pela Fundação Ayrton Senna, desenvolvidos na rede municipal de Sapiranga.

- Custo Anual por Aluno na Educação Básica em Escolas Municipais Brasileiras. Período: 2005-2006. Financiado pela Confederação Nacional de Municípios. Levantamento dos custos diretos de funcionamento de uma amostra de 200 escolas municipais brasileiras para fins de análise de perfis de custo-aluno/ano.

- Gastos em educação e desigualdades na oferta educacional no Rio Grande do Sul. Período: 2006-2008. Mapeamento e análise de fatores condicionantes da distribuição dos gastos educacionais estaduais e municipais e de resultados redistributivos do Fundef e do Fundeb nos municípios da Região Metropolitana de Porto Alegre.

- Controle na gestão de recursos financeiros da educação: quadro institucional e práticas. Financiada em parte pela Capes, mediante concessão de bolsa de estágio pós-doutoral para Nalú Farenzena, em 2009. Período: 2009-2010. Estudo do sistema e práticas político-administrativas de accountability em políticas de assistência financeira da União para programas educacionais executados em colaboração com governos subnacionais.

- Experiências de educação profissional e tecnológica integrada à educação de jovens e adultos no Estado do Rio Grande do Sul. Período: 2007-2011. Financiado pelo convênio CAPES-SETEC/PROEJA. Desenvolveu-se sob a coordenação da UFRGS e a coordenação adjunta da UFPEL e UNISINOS, em parceria com os três Institutos Federais do Rio Grande do Sul, incluindo quase a totalidade de seus campi.

- Remuneração de professores de escolas públicas da educação básica: configurações, impactos, impasses e perspectivas. Período: desde 2008. Apoio financeiro CAPES/INEP/SECAD, no âmbito do "Observatório da Educação". Análise de configurações, impactos, impasses e perspectivas decorrentes da implantação do Fundef, do Fundeb e do Piso Salarial Profissional Nacional na estrutura de remuneração dos professores da educação básica de 11 estados de cinco regiões brasileiras, de 1996 a 2012.

- Gestão das políticas de atendimento aos alunos com necessidades educacionais especiais em municípios paulistas. Período: 2008-2011. Apoio financeiro do CNPq. Descrição e análise da gestão da educação especial em municípios paulistas, focalizando as redes públicas de ensino e as instituições privadas especializadas em educação especial.

- Parcerias entre sistemas públicos e instituições do terceiro setor: Brasil, Argentina, Portugal e Inglaterra: implicações para a democratização da educação. Período: desde 2011. Apoio financeiro do CNPq. Estudo da relação entre o público e o privado, por meio da análise das parcerias entre sistemas públicos e instituições do terceiro setor e as consequências para a democratização da educação no Brasil, Argentina, Inglaterra e Portugal. Contém subprojeto sobre as políticas educacionais que envolve a relação público-privada na educação básica em todos os níveis e modalidades no Brasil, assim como a proposta de gestão pública do governo federal.

\section{Projetos de Extensão}

A projeção inicial do Núcleo foi impulsionada por atividades de pesquisa, formação continuada e disseminação de conhecimentos realizadas por demanda e/ou em cooperação com o Conselho dos Secretários Municipais de Educação (o CONSEME, entidade que integrou a UNDIME desde sua criação) e com a FAMURS, a Federação das Associações de Municípios do Rio Grande do Sul. As primeiras articulações e produções visaram sustentar 
a concepção federativa e de regime de colaboração, valorizando o sistema municipal de ensino - em oposição ao autoritarismo de uma "municipalização" - no movimento em defesa da escola pública perante as assembleias constituintes de 1987 a 1989. Durante a década de 1990 foram muitas as atividades realizadas pelo Núcleo, com o concurso de outros setores da UFRGS e de outras universidades do estado, mediante a parceria da FAMURS; mas, dentre estas, cumpre lembrar a consolidação dos fundamentos sobre a organização dos sistemas municipais de ensino, o regime de colaboração e a gestão democrática, com ênfase nos conselhos como órgãos normativos, deliberativos e de assessoramento nos sistemas de ensino e nas escolas. Nestas vivências e estudos tiveram também origem os trabalhos sobre financiamento da educação, o Fundef e a primeira pesquisa sobre custos das escolas municipais. O apoio financeiro para tais atividades foi crescente e diversificado. A par de discretos investimentos da FAMURS e da UFRGS merecem reconhecimento o projeto da OEA (já mencionado) e outros que obtiveram fundos orçamentários diversos do Ministério da Educação e da UNESCO.

Mais adiante, a destacar dada sua abrangência, há o projeto Apoio ao Desenvolvimento da Educação Básica, envolvendo parceria entre a UFRGS e o MEC, como também, de acordo com suas diferentes fases, colaborações com secretarias estaduais de educação e instâncias estaduais da UNDME.

Numa primeira fase, em 2007 e 2008, o projeto denominou-se Apoio ao Desenvolvimento da Educação Básica na rede estadual e em redes municipais de ensino do Rio Grande do Sul. O trabalho mais extenso foi o de apoio técnico direto a 142 municípios gaúchos para a elaboração do Plano de Ações Articuladas (PAR), mas abrangeu também apoio indireto a outros municípios, com a mesma finalidade e ações diversas, como as de formação para uso das tecnologias no âmbito do Plano de Desenvolvimento da Escola (PDE-Escola) e Escola Ativa.

Na segunda fase, em 2009 e 2010, o projeto - chamado Apoio ao Desenvolvimento da Educação Básica em redes municipais de ensino dos estados do Rio Grande do Sul, Santa Catarina, Alagoas e Paraíba - efetivou apoio técnico à realização do monitoramento da implementação do PAR em 500 municípios dos quatro estados. Também foi oferecido apoio indireto a municípios não priorizados dos estados do Rio Grande do Sul e Santa Catarina para o mesmo objeto.

Na terceira fase, nos anos de 2011 e 2012, o projeto - renomeado Apoio à elaboração e implementação do PAR 2011-2014 em municípios dos estados do Rio Grande do Sul e Santa Catarina - abrange apoio à elaboração e implementação do Plano de Ações Articuladas (2011-2014) a todos os municípios do Rio Grande do Sul que demandam assistência e a 65 municípios prioritários de Santa Catarina.

Essa linha de trabalho focada no fortalecimento da educação municipal gerou ou incentivou, ao longo dos anos, uma série de estudos discentes, abrangendo iniciação científica, trabalhos de conclusão de curso de graduação e especialização, dissertações e teses.

\section{Vínculos com redes ou equipes de pesquisadores de outras instituições}

O estabelecimento e consolidação de redes de pesquisa tem sido uma importante vertente de atuação do Núcleo. Ao nos somarmos a outros pesquisadores, com afinidades de objetivos e foco de interesse, no Brasil e América Latina, ganha força nosso objetivo de contribuir nas políticas em âmbito nacional e latino-americano. A troca com pesquisadores de países de outros continentes, subsídio para o alcance de tal objetivo, tem nos mostrado, guardadas as peculiaridades, semelhanças às vezes surpreendentes que reafirmam o encontrado na literatura, sobre uma tendência hegemônica na opção e ênfase em determinadas políticas, como também a marca dos contextos singulares que modulam as homogeneidades.

A seguir apontamos alguns dos projetos desenvolvidos em colaboração com pesquisadores de outras instituições.

Nos projetos Processo de implantação e impacto do FUNDEF em estados e municípios e Levantamento de custo-aluno-ano em escolas de educação básica que oferecem condições para a qualidade do ensino, trabalhamos com pesquisadores que integram a Rede Financiamento (de pesquisadores do tema do financiamento público da educação), constituída a partir dessas pesquisas. Considerando os dois projetos, atuamos junto com colegas da 
UFPR, USP, UFG, UFMG, UFBA, UFPI, UFCE, UFPA, UFPB, UFMA, UFMS, UERJ, UNEMAT e UNESP.

O projeto de pesquisa interinstitucional Programa Dinheiro Direto na escola: uma redefinição do papel do Estado na educação?, envolveu cinco instituições de diferentes regiões brasileiras (UFRGS, UNESP/Rio Claro, UCDB/MS, UFPI, UFPA). Na continuidade, o grupo foi expandido para nove instituições (UFRGS, UNICAMP, UCDB/MS, UFPI, UFPA, UFRN, UFU, UEPR, UNEMT).

No projeto Remuneração de professores de escolas públicas da educação básica trabalhamos sob a coordenação da USP, com pesquisadores de 11 estados e diversas instituições - UFPA, UFPI, UFPB, UFRN, UEMG, UFMS, UFPR, UNISUL, USP-RP, UNIFESP e UEMT.

No projeto Gestão das políticas de atendimento aos alunos com necessidades educacionais especiais em municípios paulistas a coordenação foi compartilhada com uma pesquisadora da USP.

Outro destaque é o grupo de pesquisa interinstitucional sobre a relação entre o público e o privado na educação básica com uma trajetória de estudos sobre as redefinições do papel do Estado e, nos últimos anos, mais especificamente, as mudanças nas fronteiras entre o público e o privado, tanto no que se refere à mudança de propriedade, quanto ao que continua como propriedade estatal, mas passa a ter a lógica de mercado. Inaugurado com a pesquisa Programa Dinheiro Direto na escola: uma redefinição do papel do Estado na educação?, que estudou a parceria entre sistemas públicos e o Terceiro Setor. A pesquisa teve início com o grupo estadual do Rio Grande do Sul e foi expandida com a pesquisa nacional Análise das consequências de parcerias firmadas entre municípios brasileiros e a Fundação Ayrton Senna para a oferta educacional. Atualmente, o grupo está iniciando uma nova pesquisa intitulada O Plano de Desenvolvimento da Escola - PDE-Escola e suas implicações para a gestão democrática da educação básica.

Na pesquisa Plano de Metas Compromisso Todos pela Educação: análise e avaliação da política em redes públicas municipais brasileiras trabalhamos num grupo de 23 pesquisadores, entre os quais professores da educação superior - além da UFRGS, Universidade Federal de Pelotas, Universidade Federal do Pampa, Universidade Federal da Fronteira Sul, Universidade de Passo Fundo, Universidade Estadual do Rio Grande do Sul e Faculdades Integradas de Taquara -, alunos e ex-alunos do Programa de Pós-Graduação em Educação da UFRGS, a maioria vinculada a redes públicas de educação básica.

O projeto Experiências de educação profissional e tecnológica integrada à educação de jovens e adultos no Estado do Rio Grande do Sul propiciou a integração com equipes de seis outros estados brasileiros, participantes do convênio CAPES-SETEC/PROEJA, que também pesquisaram a implantação do PROEJA. Em decorrência do projeto, criou-se uma forte rede de pesquisa com os Institutos Federais e com outras universidades do Rio Grande do Sul, como a UFPEL e UNISINOS.

Naira Lisboa Franzoi é vice-líder do grupo do CNPq Trabalho, Educação e Conhecimento e, em conjunto com pesquisadores da Fiocruz, USP e UFMG, no Brasil, e Université de Provence, na França, constitui grupo de pesquisa que investigará as políticas de certificação de saberes dos trabalhadores em ambos os países.

O Núcleo desempenhou iniciativas precursoras da Associação de Universidades grupo Montevidéu (AUGM) e do Núcleo de Educação para a Integração dessa associação, como seminários realizados na UFRGS a partir de 1988, os quais geraram relatórios e dois livros, pela Editora da UFRGS e Vozes (1990) e pela Editora da UFRGS/Goethe Institut/NEBA (1995).

Destas ações importa também lembrar a colaboração para o desenvolvimento da pós-graduação em Educação no Uruguai, desde a participação da Profa. Maria Beatriz Luce como docente em curso da Facultad de Humanidades y Ciencias de la Educación da Universidad de la República, em 1994, e, mais recentemente, em bancas de concursos docentes e de avaliação externa de projetos e instituições.

A representação da UFRGS no Núcleo Educação para a Integração (NEPI) da AUGM é composta por professoras do Núcleo desde sua criação até hoje. Mais recentemente, participamos da organização de encontros bianuais internacionais, dos programas Políticas Educativas e Políticas Linguísticas do NEPI. Nalú Farenzena assumiu a editoria do periódico Poled - Políticas Educativas, em 2010, veículo de difusão da produção 
científica de pesquisadores das universidades da AUGM.

Noutra dimensão registra-se a colaboração com universidades europeias, plasmada em projetos de pesquisa (dois projetos ALFA envolvendo universidades de Espanha, Portugal, Holanda, Itália, Argentina e Uruguai) e de intercâmbio docente e de doutorandos com as universidades do Porto e de Coimbra, sobre Política e Gestão da Educação, em especial da Educação Superior.

Em 2012 foi firmado um convênio com a Universidade de Córdoba envolvendo varias universidades brasileiras: UNICAMP, UNISINOS e UNESP no Programa Centros Associados da Pós-Graduação Brasil-Argentina (CAPG-BA).

Além disso, missões de estudos e estágios de pós-doutorado propiciaram intercâmbios, dos quais destacamos os realizados com o Instituto Internacional de Planejamento da Educação da Unesco, Paris, França; a New Jersey City University, New Jersey, e a University of Los Angeles - California, Estados Unidos; e o Institute of Education da University of London. Em fase de projeto está o relacionamento com a Universidad de La Habana (Cuba) com estudos comparativos sobre Direito à Educação e sobre Políticas e Gestão da Educação Superior.

\section{Inserção política, na comunidade acadêmica e social}

Tomando algumas reflexões de Patrick Rayou sobre a circulação de saberes entre pesquisadores e sociedade ${ }^{6}$, podemos situar o contexto atual de produção de conhecimento como o de sociedades críticas, em que os atores sociais são coprodutores das definições científicas e, desse modo, não cabe mais pensar num conhecimento produzido no campo acadêmico sendo aplicado na gestão e nas ações/políticas educacionais. Cabe, sim, a percepção de uma circulação de saberes entre pesquisadores e instâncias do sistema educacional e da sociedade em geral, do que decorre a concepção de que a construção e apropriação de saberes se dá na confluência entre teoria e interesses práticos, num contexto de inter-relação entre pesquisadores, atores sociais e condições materiais e simbólicas das ações da educação escolarizada.

Essa referência, num item em que pontuamos participações em diferentes fóruns de discussão e deliberação de política educacional, assim como em instâncias acadêmicas, é para assinalar que nosso envolvimento profissional e nosso ativismo se fizeram/fazem na compreensão das mútuas influências - e reconhecimento de coprodução - entre cientistas e demais atores sociais, ou entre cientistas do campo da gestão e da política social e cientistas de outros campos disciplinares.

No bojo desse discernimento lembramos nosso engajamento na organização, nos debates ou em mobilizações nos seguintes eventos, movimentos ou instâncias: fóruns mundiais da educação em Porto Alegre; conselhos de educação e conselhos de controle social; ações junto a secretarias de educação, educação para todos no Brasil, Plano Nacional de Alfabetização e Cidadania, discussão de planos e planejamento da educação de âmbito estadual e municipal, sindicatos e associações de trabalhadores da educação, Fórum Gaúcho em Defesa da Escola Pública, Fórum Nacional em Defesa da Escola Pública, conferências nacionais de educação (CONEDs), Associação Nacional de Política e Administração da Educação (ANPAE), Grupo de Trabalho Estado e Política Educacional da Anped, ações e estudos da Campanha Nacional pelo Direito à Educação, Plano Nacional de Educação 2001-2011, Conferência Nacional da Educação Básica (CONEB), Conferência Nacional de Educação (CONAE), movimento sindical docente na educação superior, Associação de Escolas Superiores de Formação dos Profissionais do Ensino no Rio Grande do Sul (AESUFOPE), desenvolvimento de instituições de educação superior comunitárias no Rio Grande do Sul, apoio ao desenvolvimento da pós-graduação em instituições universitárias por meio de convênios com a UFRGS.

Um registro particular tem relação com as inúmeras atividades acadêmicas de gestão, em instâncias da administração central e na Faculdade de Educação da UFRGS.

6 RAYOU, Patrick. À quoi sert la sociologie de l'éducation? Ou: La circulation des savoirs entre sociologie de l'éducation et societé. Éducation et Societé, n. 9, p. 5-11, 2002. 
De modo muito especial, damos destaque à atuação de Maria Beatriz Luce na implantação de uma das novas instituições federais no Rio Grande do Sul: a Universidade Federal do Pampa (UNIPAMPA), da qual, no período 2007-2011, foi reitora protempore.

\section{Arremate}

Vale remarcar que essa construção não conta apenas com os professores do Núcleo, mas com os inúmeros pesquisadores e orientandos que por ele passam e retornam e a ele se incorporam, menos ou mais organicamente.

Não é preciso dizer o quanto de desafiador tem sido construir permanentemente essa história, com tantas mãos, cabeças e sentenças. Os desafios são de toda ordem, desde os operacionais - tempos de encontro - até os de convivência de referenciais teórico-metodológicos diferentes. Temos a convicção de que essas diferenças não constituem fragmentação. Ao contrário, são elas que fortalecem e enriquecem nossas práticas de formação e de produção de conhecimentos.

Assim, nossa trajetória tem sido construída entre linhas convergentes e paralelas. Nossa convergência se dá em torno de princípios comuns, já explicitados, que nos são muito caros - como democratização, inclusão social, gestão democrática, justiça social. O termo paralelas pode ser tomado aqui na acepção de "que segue[m], que se desenvolve[m] na mesma direção [...], simultâneo (diz-se da realização de duas ou mais atividades correlatas, em dispositivos ou canais diferentes)" (Houaiss, 2010)7. Daí a noção de núcleo na própria designação deste grupo de pesquisa; nosso Núcleo é lugar de confluências, de afluências e, por conseguinte, de muitas influências.

Por outro lado, não podemos deixar de evocar a definição da geometria, retas que nunca se encontram, para representar a dificuldade que a sobrecarga de trabalho acarreta de criarmos tempos e espaços formais de encontros para discussão e planejamento de ações conjuntas. Em torno de cada um dos cinco professores/ pesquisadores aglutinam-se subgrupos de pesquisa, cada um, como já dito, com ênfases temáticas e abordagens teórico- metodológicas diferenciadas. Ao mesmo tempo, tanto os professores quanto os respectivos orientandos circulam entre os diferentes projetos, quase sempre de grandes dimensões. Essa circulação nas atividades da graduação, da pós-graduação, da pesquisa e da extensão acaba por suprir espaços mais formais de encontros.

Enfim, o texto, escrito a dez mãos, reflete bem a experiência do Núcleo. Recontá-la nos deu a oportunidade de fazer um balanço da nossa história e ver que, entre as linhas convergentes e paralelas pelas quais ela tem sido escrita, temos um saldo de mais acertos do que erros, mais potência que fragilidade. Seja através da formação, na pesquisa ou na nossa atuação em espaços de definição/intervenção nos rumos das políticas públicas, nos reconhecemos num papel ativo e propositivo.

\section{Referências Bibliográficas}

RAYOU, P. À quoi sert la sociologie de l'éducation? Ou: La circulation des savoirs entre sociologie de l'éducation et societé. Éducation et Societé, n. 9, p. 5-11, 2002.

Recebido em outubro de 2012 Aprovado em dezembro de 2012

7 DICIONÁRIO HOUAIS ELETRÔNICO DA LÍNGUA PORTUGUESA. Paralelo [verbete]. Rio de Janeiro: Objetiva, 2010. 